Article

\title{
Assessment of Fusarium Infection and Mycotoxin Contamination of Wheat Kernels and Flour Using Hyperspectral Imaging
}

\author{
Elias Alisaac ${ }^{1, *(\mathbb{D})}$, Jan Behmann ${ }^{1}$, Anna Rathgeb ${ }^{2}$, Petr Karlovsky ${ }^{2} \mathbb{D}$, Heinz-Wilhelm Dehne ${ }^{1,+}$ \\ and Anne-Katrin Mahlein ${ }^{3}$ \\ 1 Institute of Crop Science and Resource Conservation (INRES), Plant Diseases and Plant Protection, \\ University of Bonn, Nussallee 9, 53115 Bonn, Germany; jbehmann@uni-bonn.de (J.B.); \\ hw-dehne@uni-bonn.de (H.-W.D.) \\ 2 Molecular Phytopathology and Mycotoxin Research, University of Goettingen, Grisebachstraße 6, \\ 37077 Goettingen, Germany; anna.rathgeb@agr.uni-goettingen.de (A.R.); pkarlov@gwdg.de (P.K.) \\ 3 Institute of Sugar Beet Research (IfZ), Holtenser Landstraße 77, 37079 Goettingen, Germany; \\ Mahlein@ifz-goettingen.de \\ * Correspondence: alisaac@uni-bonn.de; Tel.: +49-228-73-68711 \\ + Professor Heinz-Wilhelm Dehne passed away during the preparation of this manuscript.
}

Received: 1 September 2019; Accepted: 19 September 2019; Published: 21 September 2019

\begin{abstract}
Fusarium head blight (FHB) epidemics in wheat and contamination with Fusarium mycotoxins has become an increasing problem over the last decades. This prompted the need for non-invasive and non-destructive techniques to screen cereal grains for Fusarium infection, which is usually accompanied by mycotoxin contamination. This study tested the potential of hyperspectral imaging to monitor the infection of wheat kernels and flour with three Fusarium species. Kernels of two wheat varieties inoculated at anthesis with F. graminearum, F. culmorum, and F. poae were investigated. Hyperspectral images of kernels and flour were taken in the visible-near infrared (VIS-NIR) (400-1000 nm) and short-wave infrared (SWIR) (1000-2500 nm) ranges. The fungal DNA and mycotoxin contents were quantified. Spectral reflectance of Fusarium-damaged kernels (FDK) was significantly higher than non-inoculated ones. In contrast, spectral reflectance of flour from non-inoculated kernels was higher than that of FDK in the VIS and lower in the NIR and SWIR ranges. Spectral reflectance of kernels was positively correlated with fungal DNA and deoxynivalenol (DON) contents. In the case of the flour, this correlation exceeded $r=-0.80$ in the VIS range. Remarkable peaks of correlation appeared at 1193, 1231, 1446 to 1465 , and 1742 to $2500 \mathrm{~nm}$ in the SWIR range.
\end{abstract}

Keywords: Triticum aestivum; wheat scab; Fusarium graminearum; Fusarium culmorum; Fusarium poae; non-invasive sensors; fungal DNA; mycotoxins; qPCR; LC-MS/MS

Key Contribution: Hyperspectral imaging can be used to pre-screen wheat harvested grain and flour for infection with Fusarium spp.

\section{Introduction}

Changes in agricultural practices in particular intensification of maize production and the wide use of reduced tillage have resulted in an increased frequency of Fusarium head blight (FHB) epidemics worldwide [1]. Recent studies have demonstrated that the main causal agents, Fusarium graminearum and F. culmorum chemotypes, tend to show geographic specificity in the main wheat production areas [2-5]. In Europe, the predominant F. graminearum chemotype is 15-acetyl-deoxynivalenol (15-ADON) whereas the predominant F. culmorum chemotype is 3-acetyl-deoxynivalenol (3-ADON) [5]. 
However, drastic changes in Fusarium chemotypes were observed in some cereal-producing countries worldwide. For example, in Argentina, an increase in 3-ADON chemotypes was observed for four years (2001-2004). However, in Uruguay, this increase was shown in 15-ADON [6,7]. Ward et al. [8] reported a shift from the 15-ADON chemotype to the 3-ADON chemotype in Canada between 1998 and 2004. In North America, new strains of F. graminearum were isolated and these isolates showed type A trichothecene production, which is new for F. graminearum $[9,10]$. These results show the high ability of Fusarium species to adapt to variety resistance. Therefore, new varieties will be needed in the future with resistance to a wide range of Fusarium species and chemotypes. The first step to achieve these varieties is to screen a large number of wheat entries against FHB. For a better understanding of the host-pathogen interaction within the screening process, it should include not only disease symptoms but also the levels of fungal DNA and mycotoxins in the kernels.

The standard method for quantifying fungal DNA in infected kernels is by quantitative real-time polymerase chain reaction (qPCR) [11], whereas the methods used to detect mycotoxin contents include immunochemical methods and analytical chemistry techniques [12,13]. However, these methods are laborious, time-consuming, and destructive. Therefore, there is a need for a fast, inexpensive, and reliable non-destructive method to pre-screen wheat kernels for FHB infection and mycotoxin contamination.

Recently, hyperspectral imaging has been introduced to identify and classify damage caused by different diseases and pests on cereal kernels. Del Fiore et al. [14] used hyperspectral imaging in the visible-near infrared (VIS-NIR) (400-1000 nm) range for early identification of toxigenic fungi, i.e., Aspergillus spp. and Fusarium spp., on commercial maize kernels. In another study, hyperspectral images in the VIS-NIR range were taken for maize kernels artificially contaminated with aflatoxin B1 (AFB1) [15]. Principal component analysis (PCA) was then combined with a stepwise factorial discriminant analysis (FDA) to discriminate control samples from samples artificially contaminated with different concentrations of AFB1. The authors were able to identify kernels contaminated with concentrations as low as $10 \mu \mathrm{g} / \mathrm{kg}$ of AFB1 [15]. Similar results were achieved by Kimuli et al. [16], who used hyperspectral imaging in the short-wave infrared range (SWIR) (1000-2500 nm) to classify AFB1 contamination in maize kernels by combining PCA with the Mahalanobis distance classifier. Additionally, AFB1 contents have been identified and classified in Aspergillus flavus-infected maize kernels by applying the support vector machine (SVM) classification approach on the PCA of the mean spectra of a single kernel in the SWIR [17].

Singh et al. [18,19] used hyperspectral imaging in the NIR from 1000 to $1600 \mathrm{~nm}$ for the detection of insect-damaged kernels of wheat during storage. They classified healthy and insect-damaged kernels with an accuracy of $85 \%$ to $100 \%$ using different classification methods.

Peiris et al. [20] applied NIR spectroscopy from 1000 to $2500 \mathrm{~nm}$ to differentiate between sound and Fusarium-damaged kernels (FDK) contaminated with different deoxynivalenol (DON) levels. They compared the spectral reflectance of the wheat kernels with that of the serial dilutions of pure DON in acetonitrile. Subsequently, commercial application of NIR spectroscopy was investigated to predict DON levels in a single wheat kernel and to sort sound kernels from FDK [21,22]. On the bulk scale, it was possible to differentiate between sample lots with different percentages of FDK using a combination of the spectral reflectance from 350 to $2500 \mathrm{~nm}$ and partial least square regression with an accuracy of $100 \%$ [23]. Using the mean spectral reflectance of a single wheat kernel in VIS-NIR from 400 to 1000 and 1000 to $1700 \mathrm{~nm}$ and linear discriminant analysis (LDA), it was possible to discriminate FKD from sound ones with an accuracy of 95\% [24,25]. Dowell et al. [26] used VIS-NIR from 400 to $1700 \mathrm{~nm}$ spectroscopy in combination with a partial least squares (PLS) regression model to predict DON and ergosterol in single wheat kernels. The same model was used in the VIS-NIR range to detect FDK in Canadian wheat, with an overall accuracy of 90\% [27]. In the VIS range, RGB images or green and red light produced from high-power pulsed light emitting diode (LED) were used in combination with LDA to classify FDK with an accuracy of $>85 \%[28,29]$. Barbedo et al. [30] developed an algorithm 
for automatic detection of FDK in wheat kernels based on hyperspectral imaging in the spectral range 528-1785 nm.

All the above studies were performed to identify Fusarium infection in wheat kernels using one species of Fusarium taking the DON content into account. To expand that knowledge base, the present study was designed to investigate the feasibility of hyperspectral imaging to screen the infection of different Fusarium species with regard to fungal DNA and different mycotoxin levels in wheat kernels and produced flour.

\section{Results}

\subsection{Effect of Fusarium Infection on the Spectral Signature of the Kernels}

Fusarium-infected kernels of both varieties showed sever symptom for all investigated Fusarium species and all spore densities (Figure 1). Non-inoculated kernels of both varieties had the same spectral signature patterns in the VIS-NIR and SWIR ranges (Figure 2). In contrast, Fusarium-infected kernels showed higher spectral reflectance along the whole spectrum compared with non-inoculated kernels.

The spectral signature of Fusarium-infected kernels differed according to the wheat variety, Fusarium species, and spore density of the inoculum (Figure 2). F. culmorum-infected kernels of 'Sonnet' from all spore densities showed identical spectral reflectance from 400 to $630 \mathrm{~nm}$. Small differences among treatments appeared in the spectral range from 630 to $700 \mathrm{~nm}$ and from 750 to $1000 \mathrm{~nm}$. In the SWIR range, these differences were pronounced from 1460 to $1850 \mathrm{~nm}$ (Figure 2). More obvious differences among treatments were shown in the case of 'Triso'. The highest reflectance of kernel samples resulted from the treatment of $1 \times 10^{4}$ spore $/ \mathrm{mL}$, whereas the lowest reflectance was for the kernels from the treatment of $5 \times 10^{5}$ spore/mL (Figure 2).
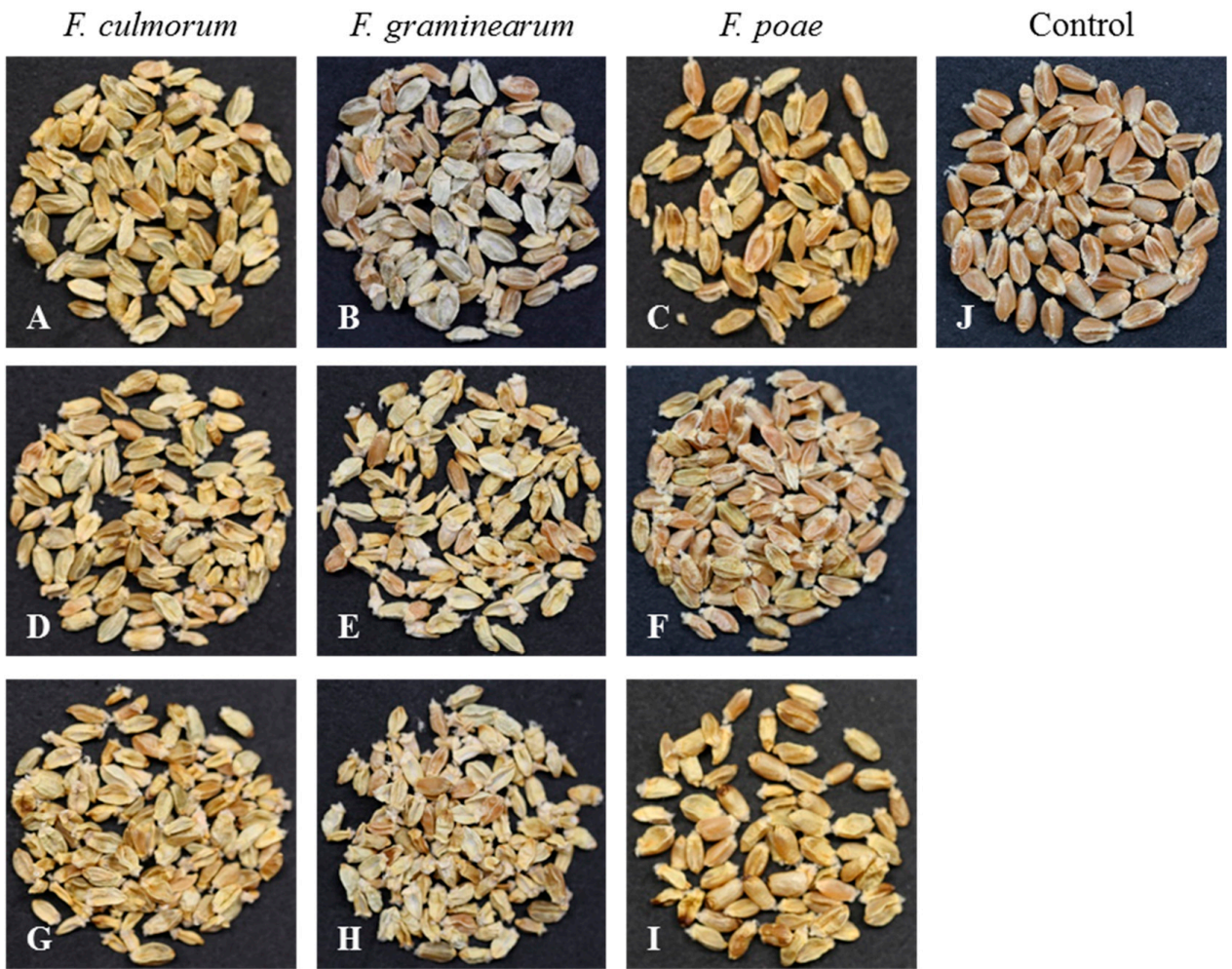

Figure 1. Summer wheat kernels cv. 'Sonett' inoculated with different spore densities $(\mathbf{A}-\mathbf{C}): 1 \times 10^{4}$ spore/mL; (D-F): $2.5 \times 10^{5}$ spore/mL; $(\mathrm{G}-\mathbf{I}): 1 \times 10^{6} \mathrm{spore} / \mathrm{mL} ;(\mathrm{J}):$ water treatment of three Fusarium species (A, D, and G: F. culmorum; B, E, and H: F. graminearum; C, F, and I: F. poae; J: Control). 

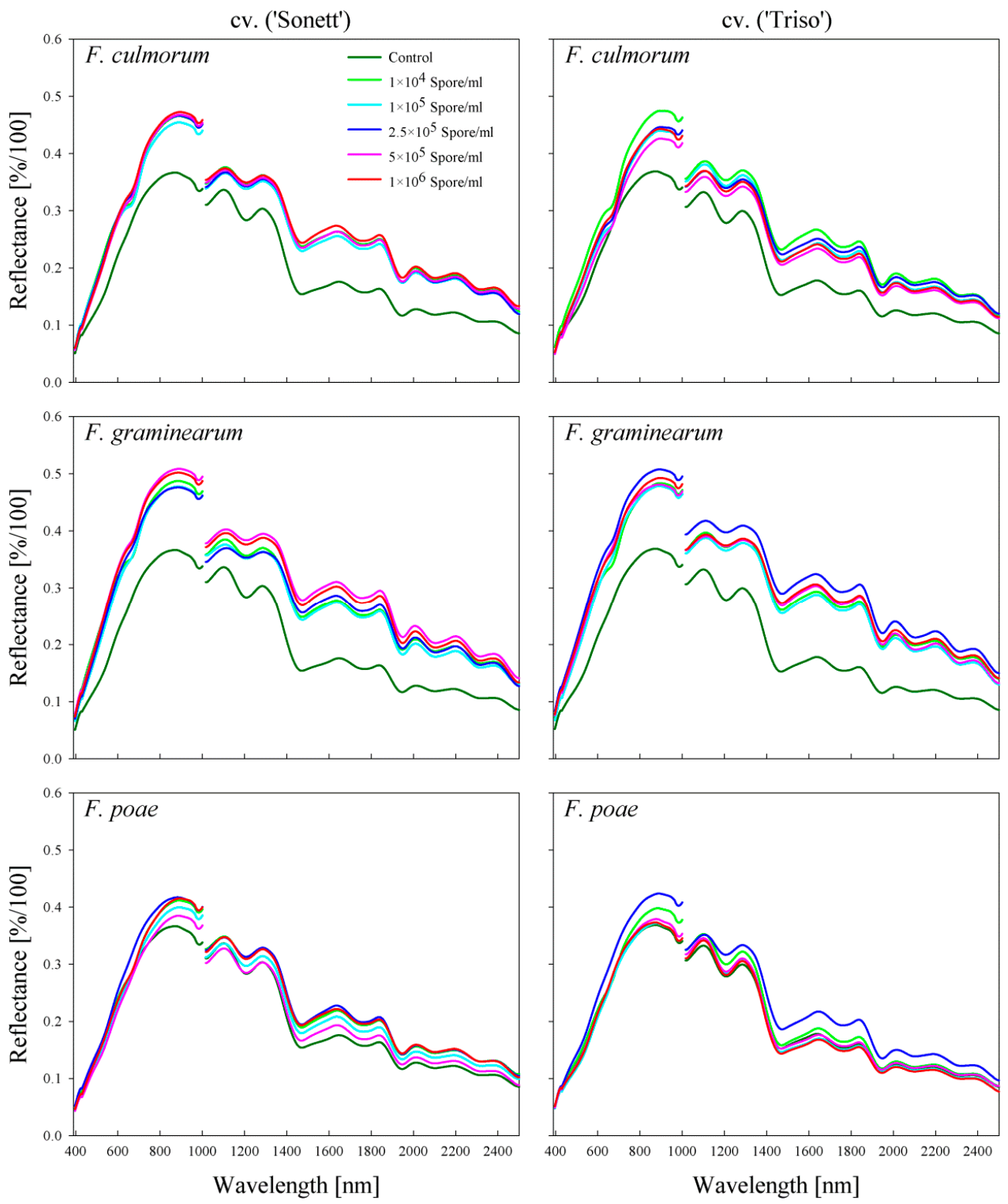

Figure 2. Spectral signature of wheat kernels cv. 'Sonett' and 'Triso' inoculated with different spore densities of three Fusarium species (F. culmorum, F. graminearum, and F. poae).

F. graminearum infection affected the same wavelengths that were affected by F. culmorum infection in the VIS-NIR range (i.e., from 400 to $630 \mathrm{~nm}$ and from 750 to $1000 \mathrm{~nm}$ ), whereas the entire SWIR range was influenced by F. graminearum infection. The treatment of $1 \times 10^{5} \mathrm{spore} / \mathrm{mL}$ resulted in the lowest reflectance of infected kernels in both varieties. The highest reflectance appeared in the treatment of $5 \times 10^{5}$ spore $/ \mathrm{mL}$ in 'Sonett' and $2.5 \times 10^{5}$ in 'Triso'. F. poae infection influenced only the NIR and the SWIR ranges. The highest reflectance was found for the treatment of $2.5 \times 10^{5} \mathrm{spore} / \mathrm{mL}$ in both varieties, and the lowest levels were with the treatment of $5 \times 10^{5}$ in 'Sonett' and $1 \times 10^{6}$ in 'Triso' (Figure 2).

\subsection{Comparison between the Spectral Signatures of the Kernels and the Produced Flour}

The spectral signature patterns of flour differed from those of kernels (Figures 2 and 3 ). The spectral reflectance of non-inoculated kernels was lower than that of infected kernels along the assessed waveband range. However, in the case of flour, the spectral reflectance of non-inoculated flour was significantly higher than that of infected flour in the VIS range (Figure 3). Obvious differences 
appeared from 630 to $670 \mathrm{~nm}$ in the spectral signatures of the flour produced from F. culmorum-and F. graminearum-infected kernels (Figure 3). Flour produced from F. poae-infected kernels showed no distinct differences in the spectral signatures in the VIS range. The treatment with the $2.5 \times 10^{5} \mathrm{spore} / \mathrm{mL}$ concentration, which resulted in the highest spectral reflectance of the infected kernels, caused the lowest spectral reflectance of the flour in both varieties (Figure 3). The spectral reflectance of the flour produced from non-inoculated kernels had the lowest values in the spectral range from 870 to $1000 \mathrm{~nm}$ in all treatments. In the SWIR range, the infection altered the wavelengths from 1100 to 1300 and 1950 to $2500 \mathrm{~nm}$. In general, flour produced from non-inoculated kernels had lower reflectance than infected ones in the SWIR range (Figure 3).
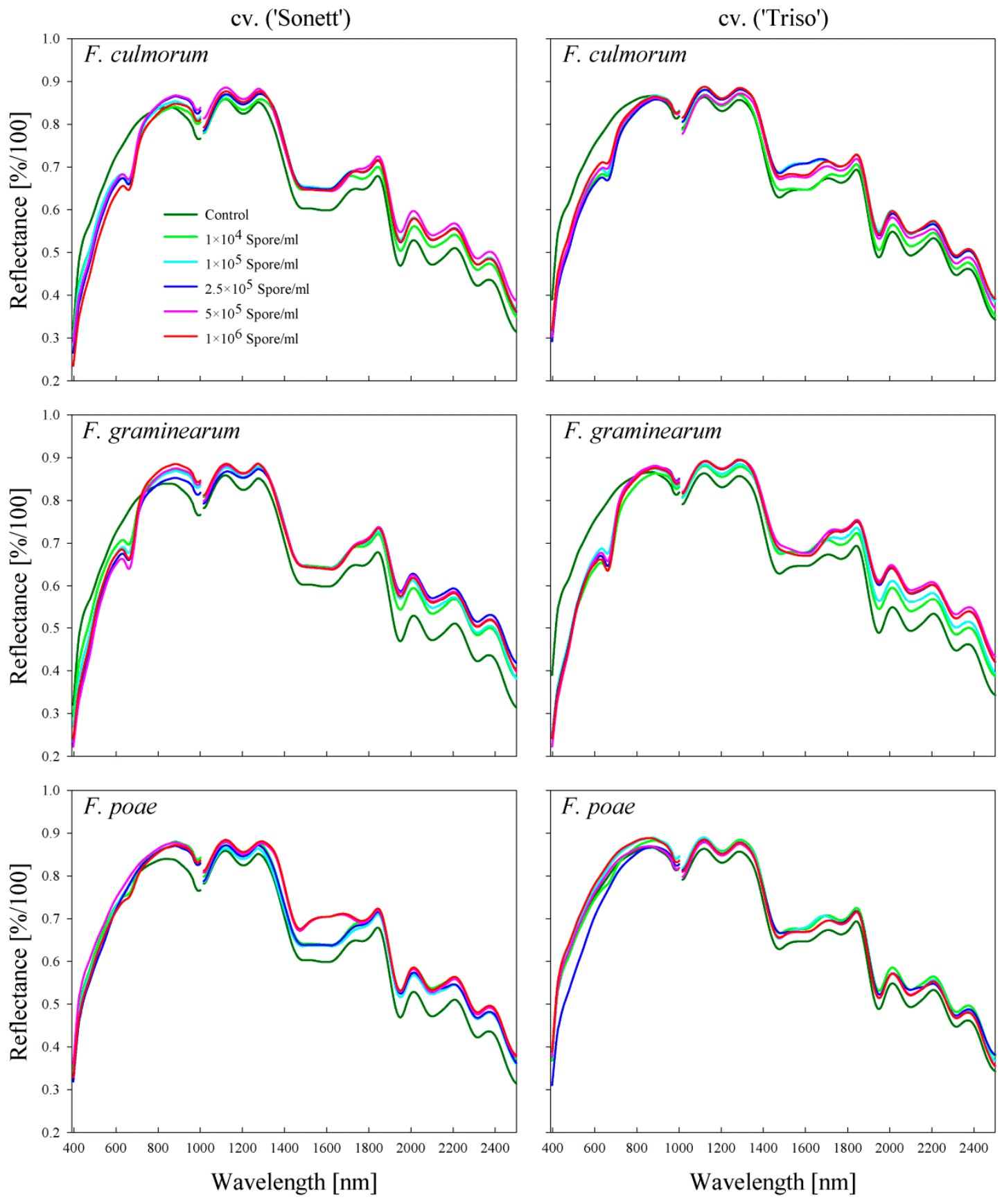

Figure 3. Spectral signature of the flour samples produced from wheat kernels cv. 'Sonett' and 'Triso' inoculated with different spore densities of three Fusarium species (F. culmorum, F. graminearum, and F. poae). 


\subsection{Fungal DNA and Mycotoxin Content in Wheat Flour}

Flour produced from non-inoculated kernels of both varieties showed neither fungal DNA nor mycotoxins for any of investigated Fusarium species.

F. culmorum produced a large amount of fungal DNA in both varieties amounting to 60 to 82 and 37 to $73 \mu \mathrm{g} / \mathrm{g}$ in 'Sonett' and 'Triso', respectively. Additionally, both varieties showed high DON content: 108 to $157 \mathrm{mg} / \mathrm{kg}$ in 'Sonett' and 44 to $81 \mathrm{mg} / \mathrm{kg}$ in 'Triso'. Fungal DNA and DON contents were not significantly different among treatments within the same variety. In addition, small amounts of 3-ADON (up to 10 and $2.7 \mathrm{mg} / \mathrm{kg}$ in 'Sonett' and 'Triso', respectively) were observed. Only in 'Sonett' were low levels of 15-ADON (0.5 mg/kg) and nivalenol (NIV) (up to $1.3 \mathrm{mg} / \mathrm{kg}$ ) detected. The variety 'Sonett' showed higher levels of fungal DNA and mycotoxins than 'Triso' (Figure 4).
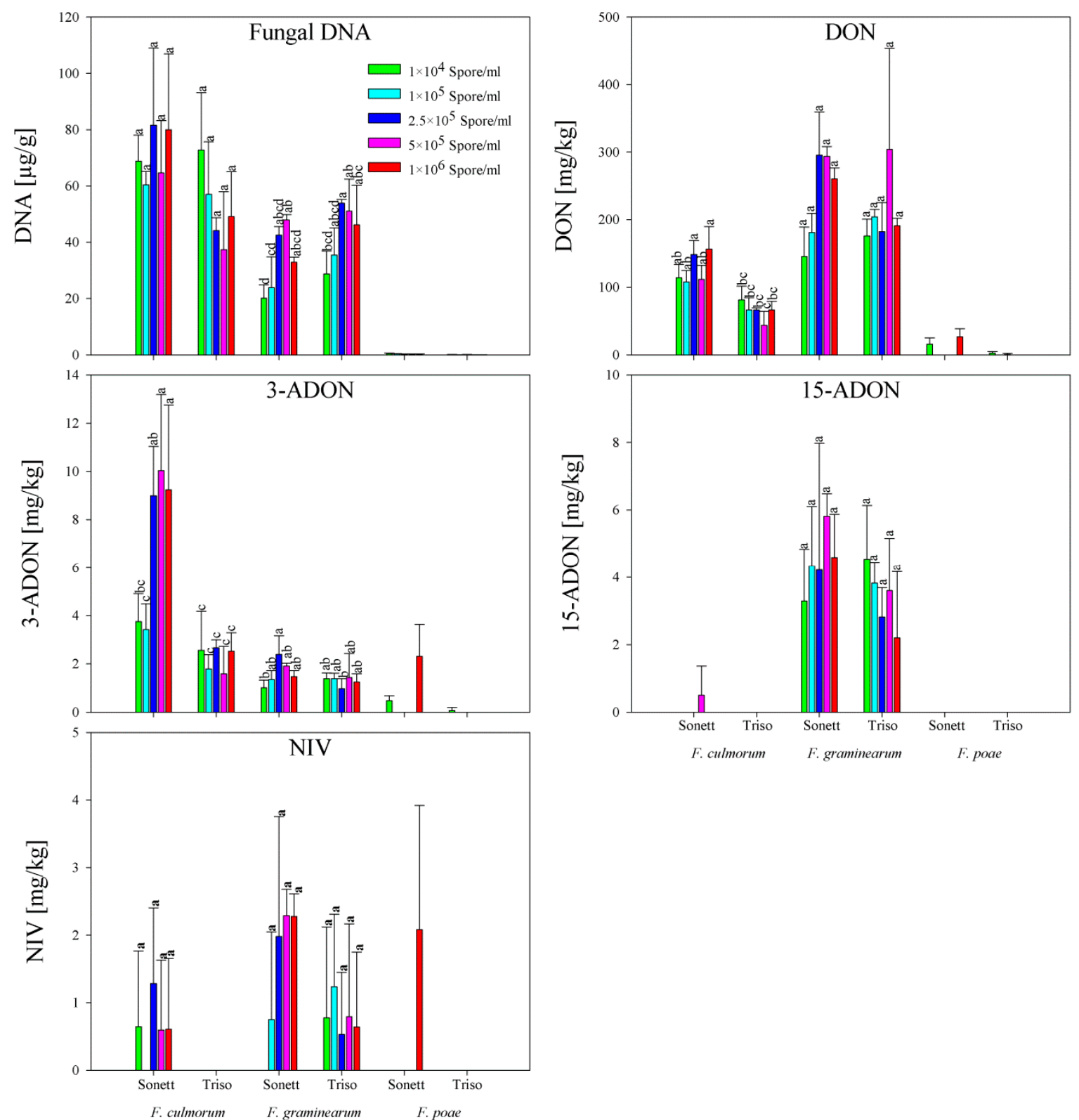

Figure 4. Fungal DNA and mycotoxin contents in the flour samples produced from wheat kernels cv. 'Sonett' and 'Triso' inoculated with different spore densities of three Fusarium species (F. culmorum, F. graminearum, and F. poae; Tukey's test; $n=3$ ). On the species scale, treatments with the same letters are not significantly different. 
Comparing with F. culmorum, F. graminearum resulted in lower fungal DNA and 3-ADON and higher DON, 15-ADON and NIV content in all treatments. In contrast with F. culmorum, 'Sonett' showed lower fungal DNA amounts 20 to $48 \mu \mathrm{g} / \mathrm{g}$ comparing with 'Triso' 29 to $54 \mu \mathrm{g} / \mathrm{g}$. DON contents ranged between 146 to $296 \mathrm{mg} / \mathrm{kg}$ in 'Sonett' and 176-304 mg/kg in 'Triso'. Maximum amounts of $2.4,4.5$ and $2.3 \mathrm{mg} / \mathrm{kg}$ have been observed for 3-ADON, 15-ADON and NIV, respectively, with no significant differences between treatments (Figure 4).

In contrast to F. culmorum and F. graminearum infections, F. poae induced very low amounts of fungal DNA that ranged between 0.1 and $0.5 \mu \mathrm{g} / \mathrm{g}$, without significant differences among treatments. Maximum concentrations of 27, 2.3, and $2.1 \mathrm{mg} / \mathrm{kg}$ for DON, 3-ADON, and NIV, respectively, were observed in 'Sonett'. In contrast, in 'Triso', 2.8 and $0.1 \mathrm{mg} / \mathrm{kg}$ for DON and 3-ADON, respectively, were recorded. No 15-ADON contamination was observed in the two varieties (Figure 4).

\subsection{Correlation between Fungal DNA and Mycotoxin Content}

The data of all samples of both varieties inoculated with different spore densities was used to calculate the correlation between fungal DNA and mycotoxin content for each Fusarium species. Table 1 shows the correlation between fungal DNA and mycotoxins content and the correlation between different mycotoxins for each Fusarium species, separately. In the case of $F$. poae infection, the correlations between fungal DNA and mycotoxin contents, and individual mycotoxin content with the other mycotoxins were not significant since most of the samples showed no mycotoxin content (Table 1).

Table 1. Pearson's correlation coefficient between fungal DNA and concentrations of different mycotoxins in the flour samples produced from wheat kernels cv. 'Sonett' and 'Triso' inoculated with different spore densities of three Fusarium species (F. culmorum, F. graminearum, and F. poae).

\begin{tabular}{cccc}
\hline Fungal DNA-Mycotoxin & F. culmorum & F. graminearum & F. poae \\
\hline Fungal DNA-DON & 0.90 & 0.80 & n.s. \\
Fungal DNA-3-DON & 0.70 & n.s. & n.s. \\
Fungal DNA-15-DON & n.s. ${ }^{*}$ & 0.51 & n.s. \\
DON-3-ADON & 0.85 & n.s & n.s. \\
DON-15-ADON & n.s. & 0.79 & n.s. \\
\hline
\end{tabular}

The correlation was calculated from the data of all samples inoculated with different spore densities of each Fusarium species $(n=30)$. * n.s. the correlation was not significant at $p \leq 0.05$.

\subsection{Correlation of Spectral Signature of Wheat Kernels to Fungal DNA and Mycotoxin Content}

The spectral reflectance of F. culmorum-infected kernels showed a high correlation of $r>0.80$ with the fungal DNA content in the spectral range 450-652 and 700-750 nm and along the SWIR range (Figure 5). This correlation reached $r=0.90$ in the spectral range 750-1000 $\mathrm{nm}$. The correlation of the spectral reflectance with DON content showed high values of $r>0.80$ in the spectral range $441-1000 \mathrm{~nm}$. This correlation was $r>0.90$ in the spectral ranges from 505 to 655 and 695 to $843 \mathrm{~nm}$. In the SWIR range, the correlation of $r>0.80$ was shown in the spectral ranges from 1200 to 1212 and 1345 to $2500 \mathrm{~nm}$, with a peak of $r>0.90$ in the spectral range 1906-2018 nm. A lower correlation of $r>0.60$ occurred for the 3-ADON content in the spectral ranges from 460 to 1000 and 1377 to $2500 \mathrm{~nm}$, with a remarkable peak of $r>0.80$ in the spectral range from 640 to $712 \mathrm{~nm}$.

The correlation of the spectral reflectance of $F$. graminearum-infected kernels with the fungal DNA content was $r>0.80$ in the spectral ranges 524-1000 and 1130-2500 nm (Figure 5). Similarly, the correlation with DON content resulted in the same values in the spectral ranges 558-814 and $1377-2031 \mathrm{~nm}$. The correlation of the spectral reflectance with the DON derivative contents was lower compared with the DON content. This correlation ranged between $r=0.60-0.70$ in the spectral ranges 474-1000 and 1358-2500 $\mathrm{nm}$ for the 3-ADON content, and between $r=0.62$ and 0.76 along the electromagnetic spectrum for 15-ADON. No correlation between the spectral reflectance and NIV was observed. 

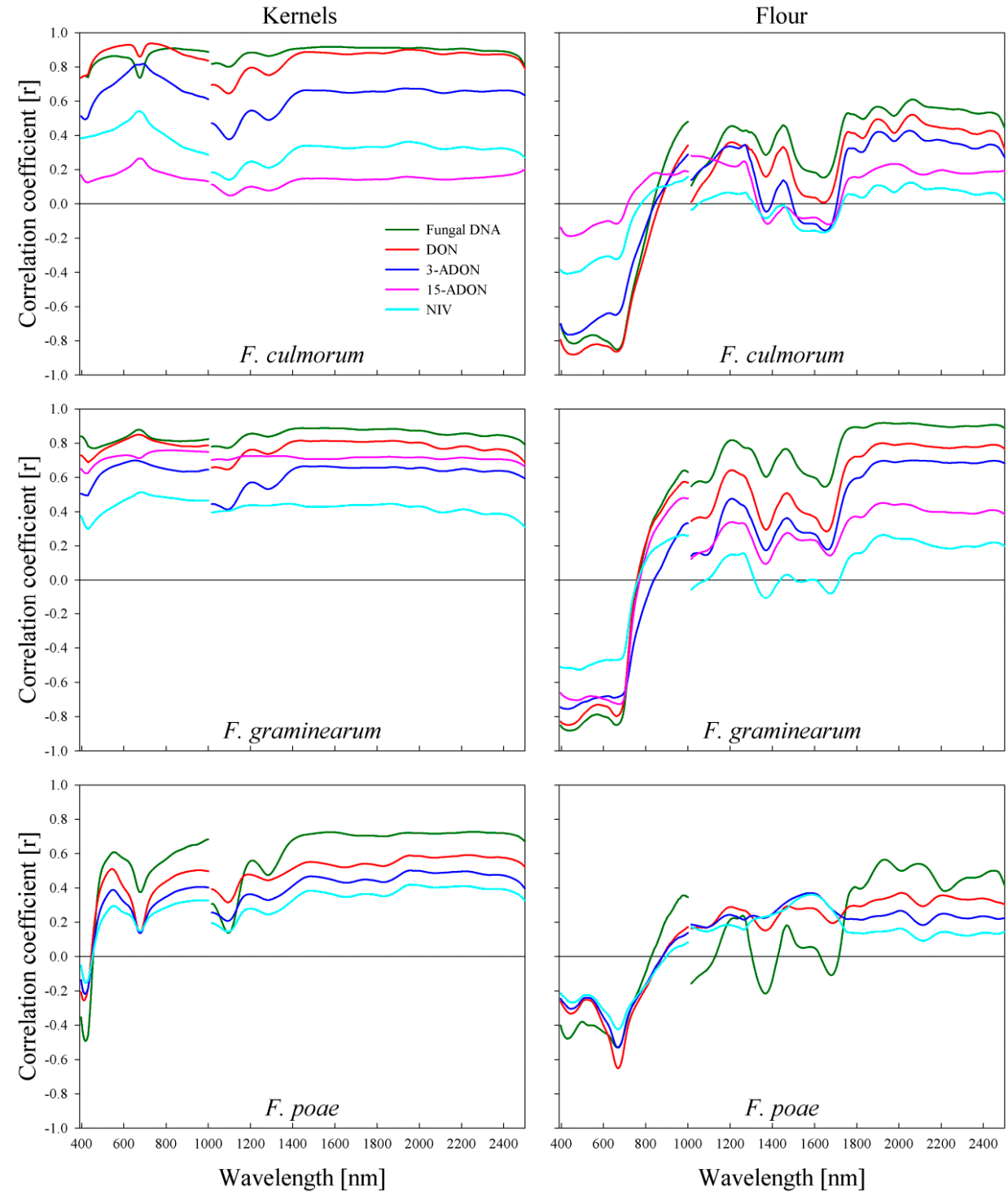

Figure 5. Pearson's correlation coefficient between the spectral signature of wheat kernels cv. 'Sonett' and 'Triso' (left) inoculated with different spore densities of three Fusarium species and wheat flour produced from these kernels (right) in relation to fungal DNA and various mycotoxin levels.

The spectral reflectance of $F$. poae-infected kernels showed a lower correlation with the fungal DNA content compared with F. culmorum and F graminearum (Figure 5). A correlation of $r>0.60$ in the spectral ranges $538-572$ and $828-1000 \mathrm{~nm}$ was proven. In the SWIR range, the correlation ranged between $r=0.60$ and 0.73 in the spectral range $1350-2500 \mathrm{~nm}$.

\subsection{Correlation of Spectral Signature of Wheat Flour to Fungal DNA and Mycotoxin Content}

The spectral reflectance of the produced flour resulted in negative correlations with the fungal DNA and mycotoxin contents in the VIS range. In addition, a positive correlation in the SWIR range and no significant correlation in the NIR range were confirmed (Figure 5).

The spectral reflectance of flour produced from F. culmorum-infected kernels exhibited a high negative correlation of $r>0.80$ with the fungal DNA content in the spectral ranges 427-494 and 601-692 nm. In the SWIR range, two remarkable peaks of $r>0.45$ appeared in the spectral ranges 1193-1231 and 1446-1465 nm. The correlation increased to $r>0.51$ in the spectral range 1742-2500 nm and reached $r=0.61$ in 2050 to $2075 \mathrm{~nm}$ (Figure 5). The correlation with DON content was higher than 
the correlation with the fungal DNA in the VIS range, and lower in the SWIR range. The correlation reached $r>0.85$ in the spectral ranges 427-494 and 655-675 nm; however, the highest value of $r=0.52$ appeared in the range 2050-2075 $\mathrm{nm}$. The correlation with 3-ADON content showed decreasing values with an increasing wavelength in the VIS range and ranged between 0.70 and 0.50 , with no remarkable correlation in the SWIR range (Figure 5).

The spectral reflectance of flour produced from F. graminearum-infected kernels had a higher correlation with fungal DNA than that of F. culmorum. The highest negative correlation of $r>0.85$ appeared in the spectral ranges 397-494 and 652-670 nm. Likewise, for F. culmorum, the same peaks appeared in the spectral ranges 1193-1231 and 1446-1465 nm, with a higher correlation of $r>0.81$ and $r>0.76$, respectively, and increased to $r>0.86$ in the spectral range 1742-2500 nm (Figure 5). The correlation with DON content showed values of $r>0.80$ and $r>0.79$ in the spectral ranges 397-494 and 655-675 nm, respectively. In the SWIR range, the correlation reached $r>0.64, r>0.50$, and $r=0.65$ in the spectral ranges 1193-1231, 1446-1465, and 1742-2500 nm, respectively. In the VIS range, the correlation with 3-ADON showed a decreasing value with an increasing wavelength, with a peak of 0.76 in the spectral range $422-435 \mathrm{~nm}$. While, it showed the reverse with $15-\mathrm{ADON}$, with a peak of $r=0.69$ in the spectral range $635-700 \mathrm{~nm}$. The correlation with 3-ADON reached $r>0.46$ and $r>0.60$ in the spectral ranges $1193-1231$ and $1800-2500 \mathrm{~nm}$, respectively. In contrast, no correlation was observed with 15-ADON in the SWIR range. The NIV content showed no significant correlation with the spectral reflectance of the produced flour, and the highest negative correlation of $r=0.53$ was achieved in the spectral range 475-497 nm (Figure 5).

The spectral reflectance of flour produced from F. poae-infected kernels had the highest correlations with fungal DNA of $r=0.53$ and $r=0.56$ in the spectral ranges 664-672 and 1912-1950 nm, respectively (Figure 5).

\section{Discussion}

The symptoms of Fusarium infection on infected kernels result in a reduction of the thousand kernel weight, shriveling, pinkish discoloration, and chalky appearance [1,31]. Several studies showed the applicability of hyperspectral imaging for the detection of Fusarium-damaged kernels or spikelets [20-25,32,33]. The reflected light in the VIS range shows the tissue pigments; the NIR range represents the tissue structure, while the SWIR range characterizes the chemical compounds [34]. In the current study, the reflectance of infected kernels was higher than that of non-infected ones in the VIS-NIR range. This is attributed to the discoloration of infected kernels compared with healthy ones, and to the changes in the kernel structure due to infection. This is in accordance with previous studies that proved a lower reflectance of healthy wheat kernels compared with Fusarium-damaged kernels in the VIS-NIR range $[23,25,27]$. Former studies demonstrated an increase in the protein, starch, starch lipids, and non-starch lipids in Fusarium-infected kernels [35-37]. The reflectance of infected kernels was higher than of healthy ones in the SWIR range, which is consistent with the results of [23-25]. This is due to the changes in the chemical contents of the infected kernels due to Fusarium infection.

The quality of wheat flour depends strongly on gluten proteins [38]. Fusarium infection leads to substantial changes in the storage contents of wheat kernels [39], and consequently, flour appearance. Histological investigation proved high degradation in the starch granules and the protein matrix of the endosperm of Fusarium-infected kernels [40]. Gärtner et al. [41] showed a positive correlation $(r=0.93)$ between the disease severity and ash content (minerals like potassium and calcium salts) of $F$. culmorum-infected kernels. This explains the lower reflectance of flour from infected kernels compared with that from non-infected kernels in the current study.

The study of Hellin et al. [42] showed a high correlation between the spore density in the air above the canopy and DON concentration and disease incidence of F. graminearum under field conditions. In the current study, no significant differences were found between inoculum density and fungal DNA and mycotoxin concentrations in the infected kernels with all Fusarium species. This is due to the differences in the experimental conditions of these studies. While the study of Hellin et al. [42] was 
implemented under natural conditions in the field and without incubation, the current study was implemented under greenhouse conditions with incubation for $48 \mathrm{~h}$ after inoculation. Under these optimal conditions for the pathogens, the lowest number of spores was enough to induce infection with maximum disease severity, which could not be further increased using higher spore densities.

In this study, F. culmorum isolate produced DON and 3-ADON as secondary metabolites, while F. graminearum produced DON, 3-ADON, and 15-ADON. This is in accordance with the results that showed the ability of F. graminearum to produce DON, 3-ADON, and 15-ADON simultaneously [43]. Small amounts of NIV were detected in some samples. This is due to a side infection with NIV producer, since the isolates used in this study are DON producers. The results of the current study showed high correlations of $r=0.90, r=0.70$, and $r=0.85$ between fungal DNA-DON, fungal DNA-3-ADON, and DON-3-ADON, respectively, for F. culmorum. In addition, correlations of $r=0.80, r=0.51$, and $r=0.79$ between fungal DNA-DON, fungal DNA-15-ADON and DON-15-ADON, respectively, for $F$. graminearum were observed. This indicates that the major source of DON, 3-ADON, and 15-ADON in the samples resulted from the isolates used for inoculation, and not from a spontaneous infection. Moreover, it shows that these isolates produce trichothecenes in the same ratio in vitro and in vivo. In the case of F. poae, no significant correlation was seen because it was less effective in inducing infection in both wheat varieties. This corresponds to the results of previous studies that showed high correlations between the fungal DNA of F. culmorum and F. graminearum and the amount of DON in infected kernels of wheat and barley. In addition, a positive correlation between the fungal DNA of $F$. poae and NIV content was documented. However, on the species scale, it was shown previously that $F$. poae was less effective in term of fungal DNA and mycotoxin production [44-46].

The results of the current study showed higher correlations in the NIR range compared with the VIS range between the spectral reflectance of wheat kernels and the fungal DNA and DON contents for all Fusarium species. This is in accordance with the results of Shahin and Symons [27] that proved no specific wavelengths correlated to Fusarium infection in wheat kernels in the VIS-NIR ranges. The results of Delwiche et al. [25] showed that the spectral ranges 502-678 nm, 1198-1496 nm, and 1420-1560 nm were affected by Fusarium infection. They showed that the NIR range was superior to the VIS range to identify Fusarium-infected kernels. They attributed this to the transformation of the endosperm compound into fungal characteristic compounds, i.e., chitin and ergosterol. Delwiche [47] showed that the wavelengths 1182 and $1242 \mathrm{~nm}$ gave the best results to discriminate sound kernels from Fusarium-damaged kernels. The study of Delwiche and Hareland [24] showed that the spectral range 1130-1190 $\mathrm{nm}$ was strongly affected by Fusarium infection, with a peak at $1158 \mathrm{~nm}$. In addition, the spectral range 1300-1450 nm was affected with a remarkable peak at $1400 \mathrm{~nm}$. In the current study, the same peak of correlation between the spectral reflectance and the fungal DNA and DON contents appeared in the spectral range 1200-1212 nm. However, a higher correlation has been proven in the spectral range 1350-2500 $\mathrm{nm}$ for all Fusarium species.

In the current study, more pronounced peaks of correlations appeared between the spectral reflectance of wheat flour and fungal DNA and DON contents compared with wheat kernels. Dowell et al. [26] showed that the wavelengths of 750 and $950 \mathrm{~nm}$ were characteristic bands in the VIS-NIR range for predicting Fusarium-damaged kernels. They attributed this to the effect of Fusarium infection on the starch and protein content of wheat kernels, which absorb the radiation of these bands. In the current study, two pronounced peaks between the flour spectral reflectance and fungal DNA and DON contents were shown in the spectral ranges 427-494 and 655-670 nm. No correlation was found in the NIR range, which indicates the tissue structure. This is attributed to the destruction of the kernel tissue structure during grinding.

In the SWIR, Peiris et al. [20] showed that the absorption bands of different DON concentrations dissolved in acetonitrile were in 1390 to 1440 and 1880 to $1950 \mathrm{~nm}$. They proved clear peaks at $1414 \mathrm{~nm}$ due to the $-\mathrm{OH}$ groups and $1906 \mathrm{~nm}$ due to the $-\mathrm{C}=\mathrm{O}$ and $\mathrm{R}-\mathrm{OH}$ groups of the DON molecule. Moreover, they proved that the bands 1195, 1208, 1365, 1445, 1700, 1905, and $2001 \mathrm{~nm}$ were characteristic bands for Fusarium-infected kernels. This is in accordance with the results of the current study, which showed 
two remarkable peaks of correlation between the spectral signature of the flour and fungal DNA and DON contents in the spectral ranges 1193-1231 and 1446-1465 nm, in addition to a high correlation along the spectral range 1742-2500 $\mathrm{nm}$.

\section{Conclusions}

This study showed that Fusarium infection influences the spectral signatures of wheat kernels and flour produced from them. Correlations between the spectral data of infected kernels and corresponding flour, fungal DNA, and individual mycotoxins were documented. This shows the feasibility of hyperspectral imaging to screen wheat kernels and flour for Fusarium infection. Previous results showed the suitability of hyperspectral imaging to phenotype Fusarium head blight on wheat at the spike scale. Combined with the results of this study, hyperspectral imaging provides the breeder with an integrated tool to phenotype Fusarium infection on the spike scale and in harvested grain, accelerating the phenotyping process.

\section{Materials and Methods}

\subsection{Plant Material}

Two varieties of spring wheat (Triticum aestivum L.) differing in their susceptibility to FHB were grown under greenhouse conditions: 'Triso' moderately resistant from DSV, Lippstadt, Germany, and 'Sonett' moderately susceptible from Syngenta, Basel, Switzerland (Descriptive List of Varieties, Bundessortenamt, Germany, 2017). The growth substrate was a mixture of 1 sand:3 horizon C:6 potting substrate ED 73 (Einheitserde, Sinntal-Altengronau, Sinntal, Germany). Three kernels per pot were planted in $12 \times 12 \times 20 \mathrm{~cm}$-sized pots. After germination, the plants were thinned to two plants per pot and the plants were supported by wooden sticks. Environmental conditions in the greenhouse were: Photoperiod of 16/8 h (day/night) obtained from supplemental artificial light $\left(>300 \mu \mathrm{mol} \mathrm{m}^{-2} \mathrm{~s}^{-1}\right.$, Philips SGR 140, Hamburg, Germany); a temperature of $20 \pm 2{ }^{\circ} \mathrm{C}$; and $50-70 \%$ relative humidity. The plants were watered when necessary.

\subsection{Plant Pathogens and Inoculation Techniques}

Isolates of three Fusarium species stored at $-80{ }^{\circ} \mathrm{C}$ were used in this study: Fusarium graminearum, isolate S.19 produced 69\% 15-ADON and 31\% DON, and F. culmorum, isolate 3.37 produced 68\% 3-ADON and $32 \%$ DON on rice culture. They were originally isolated from infected wheat kernels in an experimental field (Campus Klein-Altendorf, Rheinbach, Germany) in 2011 and 2004, respectively. F. poae, isolate EC15 was taken from the INRES (Plant Diseases and Plant Protection, University of Bonn, Germany) mycological collection. Pathogen cultivation and inoculum preparation were performed according to Alisaac et al. [32]. The spore suspension was diluted to $1 \times 10^{6}$ spore/mL using a Fuchs-Rosenthal chamber. Spore densities of $1 \times 10^{4}, 1 \times 10^{5}, 2.5 \times 10^{5}, 5 \times 10^{5}$, and $1 \times 10^{6}$ spore/mL were derived from the stock spore suspension and used in inoculation. Each treatment consisted of one pot with two plants of each variety with more than 10 spikes per pot at the anthesis growth stage, GS 61-65 [48]. Pots were randomly distributed on the table in the middle of the greenhouse in order to guarantee the homogeneity of the surrounding environment. Spray inoculation was done as described in Alisaac et al. [32]. Control plants were mock inoculated with water. At harvest, spikes were collected and threshed manually, and the resulting kernels prepared for hyperspectral measurement (Figure 1). After acquiring the hyperspectral images of the kernels, they were ground using a lab grinder (Retsch MM 200, Haan, Germany). The produced flour was measured using the same hyperspectral imaging setup with the same settings.

\subsection{Hyperspectral Measurements}

Hyperspectral measurements were done in a darkened room. The objects were illuminated using an artificial light produced from six ASD-Pro-Lamps (Analytical Spectral Devices Inc., Boulder, CO, USA) with a $45^{\circ}$ vertical angle to the objects. The images were acquired in the visible-near infrared 
(VIS-NIR) range from 400 to $1000 \mathrm{~nm}$ using the hyperspectral camera ImSpector V10E (Spectral Imaging Ltd., Oulu, Finland). In total, 211 hyperspectral bands were recorded using a spectral binning of 4. In the short-wave infrared (SWIR) from 1000 to $2500 \mathrm{~nm}$, a SWIR-Camera (ImSpector N25E, Spectral Imaging Ltd., Oulu, Finland) was used. In total, 256 hyperspectral bands were recorded using a spectral binning of 1. A motorized line scanner (Velmex BiSlide, Velmex Inc., Bloomfield, Ontario County, NY, USA) was used to move the cameras and the illumination system over the object. The software SpectralCube (Spectral Imaging Ltd., Oulu, Finland) was applied to adjust the settings of the camera and the motorized line scanner. To attain stable measuring conditions, the cameras and the illumination system were preheated for $30 \mathrm{~min}$ before the measurements. For more details about the imaging system and data processing, see Alisaac et al. [32]. To acquire the hyperspectral images, a black Petri dish (Brightic, Nagymaros, Hungary) was used as a background for the kernel and flour measurements. This Petri dish has low reflectance of $<5 \%$ in the spectral range of 400 to $2500 \mathrm{~nm}$. For flour measurement, black rings of a $1 \mathrm{~mm}$ height were filled with the flour in order to obtain a homogeneous topography for the flour surface. Four images were made to calculate the reflectance of the object sample: (i) A white reference image using a white barium-sulfate bar (Spectral Imaging Ltd., Oulu, Finland), which reflects $~ 99 \%$ of the light; (ii) a dark current image by closing the shutter of the camera at the same exposure time of the white reference; (iii) the image of the object sample; and (iv) a second dark current image at the same exposure time of the object sample. The open source software HSVaP ("Hyperspectral Visualization and Processing") was used for masking and visualizing the image data (available at https://github.com/janBehmann/HSVAP). The mean spectral reflectance was calculated using MATLAB 2013a (MathWorks, Natick, MA, USA).

\subsection{DNA Extraction and Fungal DNA Quantification}

Total DNA was extracted from $20 \mathrm{mg}$ of flour according to a cetyltrimethylammonium bromide method and precipitated with polyethylene glycol [49]. The pellets were washed twice with $80 \%(v / v)$ ethanol, dried in vacuum at $30^{\circ} \mathrm{C}$, dissolved in $50 \mu \mathrm{L}$ TE-buffer ( $10 \mathrm{mM}$ Tris, $1 \mathrm{mM}$ EDTA, pH 8.0), and diluted 100-fold in water for qPCR. Three-fold dilution series of pure fungal DNA from 0.3 to $100 \mathrm{pg}$ per reaction were used as standards. A real-time PCR thermocycler CFX 384 (Biorad, Rüdigheim, Germany) was used for fungal DNA quantification using the primers listed in Table 2. The components of the reaction mixture were: Taq Polymerase with ThermoPol Buffer $\left(20 \mathrm{mM}\right.$ Tris- $\mathrm{HCl}, 10 \mathrm{mM}\left(\mathrm{NH}_{4}\right)_{2} \mathrm{SO}_{4}$, $10 \mathrm{mM} \mathrm{KCl}, 2 \mathrm{mM} \mathrm{MgSO}_{4}, 0.1 \%$ Triton-X-100, pH 8.8 at $\left.25^{\circ} \mathrm{C}\right) ; 0.15 \mathrm{mM}$ of each dNTP; $2.5 \mathrm{mM} \mathrm{MgCl} 2$ (Bioline, Lückenwalde, Germany); $0.3 \mu \mathrm{m}$ of each primer; and SYBR Green I (Invitrogen, Karlsruhe, Germany). The PCR started with initial denaturation at $95.0^{\circ} \mathrm{C}$ for $2 \mathrm{~min}$, followed by 35 cycles according to Table 2. The final elongation was done at $68.0^{\circ} \mathrm{C}$ for $5 \mathrm{~min}$. Melting curves were generated after amplification by heating PCR products to $95.0^{\circ} \mathrm{C}$ for $1 \mathrm{~min}$, cooling to $55.0^{\circ} \mathrm{C}$ for $1 \mathrm{~min}$, then tardily raising the temperature $0.5^{\circ} \mathrm{C} / 10 \mathrm{~s}$ according to Table 2 . The fluorescence was measured continuously. Because of degradation of wheat DNA in infected kernels, the amount of fungal DNA per gram of dry flour rather than the ratio of fungal to wheat DNA was used as a measure of fungal colonization.

\subsection{Mycotoxin Extraction and Quantification}

Mycotoxins were extracted from $350 \mathrm{mg}$ of flour per treatment in $3.5 \mathrm{~mL}$ of acetonitrile-water $(84: 16, v / v)$. The mixture was vortexed, shaken overnight, and centrifuged at $4500 \mathrm{~min}^{-1}$. One $\mathrm{mL}$ of the supernatant was transferred to a 2-mL Eppendorf tube and dried at $40^{\circ} \mathrm{C}$. The dry residue was re-suspended in $1 \mathrm{~mL}$ of methanol- $1 \%$ formic acid in water $(25: 75, v / v)$, and sonicated in an ultrasonic bath until completely dissolved. Blank (control) samples of wheat flour were prepared in the same way. The following mycotoxin standards were used (Table 3): Nivalenol (NIV), deoxynivalenol (DON), 3-acetyl-deoxynivalenol (3-ADON) and 15-acetyl-deoxynivalenol (15-ADON), HT-2 toxin, T-2 toxin, zearalenone (ZEA), enniatin A1, and enniatin B1. 
Table 2. Forward and reverse primers sequences; denaturation, annealing, elongation, and melting curve temperatures of the primer used to amplify specific fragments of the fungal DNA of Fusarium culmorum, F. graminearum, and F. poae on wheat kernels and in flour.

\begin{tabular}{|c|c|c|c|c|c|c|c|c|c|c|c|c|}
\hline \multirow[t]{2}{*}{ Pathogen } & \multicolumn{2}{|c|}{ Denaturation } & \multicolumn{2}{|c|}{ Annealing } & \multicolumn{2}{|c|}{ Elongation } & \multicolumn{2}{|c|}{ Melt Curve } & \multicolumn{4}{|c|}{ Primers } \\
\hline & ${ }^{\circ} \mathrm{C}$ & $\min$ & ${ }^{\circ} \mathrm{C}$ & $\min$ & ${ }^{\circ} \mathrm{C}$ & $\min$ & ${ }^{\circ} \mathrm{C}$ & ${ }^{\circ} \mathrm{C}$ & Primer name & Primer sequence $\left(5^{\prime}-3^{\prime}\right)$ & Amplified fragment & Reference \\
\hline F. culmorum & 94.0 & $0: 20$ & 62.0 & $0: 40$ & 68.0 & $0: 45$ & 65.0 & 95.0 & $\begin{array}{l}\text { OPT18 F } \\
\text { OPT18 R }\end{array}$ & $\begin{array}{l}\text { GATGCCAGACCAAGACGAAG } \\
\text { GATGCCAGACGCACTAAGAT }\end{array}$ & $472 \mathrm{bp}$ & Schilling et al. [49] \\
\hline F. graminearum & 94.0 & $0: 30$ & 61.0 & $0: 30$ & 68.0 & $0: 30$ & 55.0 & 95.0 & $\begin{array}{l}\text { Fg16N F } \\
\text { Fg16N R }\end{array}$ & $\begin{array}{l}\text { ACAGATGACAAGATTCAGGCACA } \\
\text { TTCTTTGACATCTGTTCAACCCA }\end{array}$ & $280 \mathrm{bp}$ & Nicholson et al. [50] \\
\hline F. poae & 94.0 & $0: 35$ & 62.5 & $0: 30$ & 68.0 & $0: 35$ & 55.0 & 95.0 & $\begin{array}{l}\text { Fp82 F } \\
\text { Fp82 R }\end{array}$ & $\begin{array}{l}\text { CAAGCAAACAGGCTCTTCACC } \\
\text { TGTTCCACCTCAGTGACAGGTT }\end{array}$ & $220 \mathrm{bp}$ & Parry and Nicholson [51] \\
\hline
\end{tabular}


Table 3. Mass transitions, recoveries, and the limits of detection and quantification of mycotoxins in flour samples produced from wheat kernels cv. 'Sonett' and 'Triso' inoculated with different spore densities of three Fusarium species (F. culmorum, F. graminearum, and F. poae).

\begin{tabular}{|c|c|c|c|c|c|c|c|c|}
\hline Toxin & Obtained From & Molecular Ion & Parent Ion & Collision Energy [V] & Product Ions & $\begin{array}{c}\mathrm{LOD}^{*} \\
{[\mathrm{mg} / \mathrm{kg}]}\end{array}$ & $\begin{array}{c}\mathrm{LOQ}^{*} \\
{[\mathrm{mg} / \mathrm{kg}]}\end{array}$ & $\begin{array}{c}\text { Recovery } * * * \\
\%\end{array}$ \\
\hline NIV & $\begin{array}{c}\text { Merck } \\
\text { (Darmstadt, Germany) }\end{array}$ & {$[\mathrm{M}-\mathrm{H}]^{-}$} & 357.1 & $\begin{array}{l}10 \\
10\end{array}$ & $\begin{array}{c}311.1 \\
281.1 * *\end{array}$ & 0.007 & 0.025 & 89 \\
\hline $\mathrm{DON}$ & $\begin{array}{c}\text { Merck } \\
\text { (Darmstadt, Germany) }\end{array}$ & {$[\mathrm{M}+\mathrm{H}]^{+}$} & 297.1 & $\begin{array}{c}4 \\
64\end{array}$ & $\begin{array}{l}249.1 * * \\
91.2\end{array}$ & 0.006 & 0.018 & 113 \\
\hline 3-ADON & $\begin{array}{c}\text { Merck } \\
\text { (Darmstadt, Germany) }\end{array}$ & {$[\mathrm{M}+\mathrm{H}]^{+}$} & 339.2 & $\begin{array}{l}8 \\
8\end{array}$ & $\begin{array}{l}231.1^{* *} \\
203\end{array}$ & 0.022 & 0.072 & 110 \\
\hline 15-ADON & $\begin{array}{c}\text { Merck } \\
\text { (Darmstadt, Germany) }\end{array}$ & {$[\mathrm{M}+\mathrm{H}]^{+}$} & 339.2 & $\begin{array}{l}10 \\
10\end{array}$ & $\begin{array}{l}261.0^{* *} \\
203\end{array}$ & 0.07 & 0.23 & 111 \\
\hline HT-2 & $\begin{array}{l}\text { Enzo Life Sciences } \\
\text { (Lörrach, Germany) }\end{array}$ & {$[\mathrm{M}+\mathrm{Na}]^{+}$} & 447 & $\begin{array}{l}17 \\
17\end{array}$ & $\begin{array}{l}345.1^{* * *} \\
285\end{array}$ & 0.029 & 0.097 & 96 \\
\hline $\mathrm{T}-2$ & $\begin{array}{l}\text { Enzo Life Sciences } \\
\text { (Lörrach, Germany) }\end{array}$ & {$[\mathrm{M}+\mathrm{Na}]^{+}$} & 489.2 & $\begin{array}{c}98 \\
142 \\
\end{array}$ & $\begin{array}{c}128.1 \\
115.1^{* *}\end{array}$ & 0.029 & 0.092 & 119 \\
\hline ZEA & $\begin{array}{l}\text { Romer Labs } \\
\text { (Tulln, Austria) }\end{array}$ & {$[\mathrm{M}+\mathrm{H}]^{+}$} & 319.2 & $\begin{array}{l}12 \\
12\end{array}$ & $\begin{array}{c}301.1 \\
283.0 * *\end{array}$ & 0.098 & 0.322 & 76 \\
\hline Enniatin A1 & $\begin{array}{c}\text { Merck } \\
\text { (Darmstadt, Germany) }\end{array}$ & {$[\mathrm{M}+\mathrm{H}]^{+}$} & 668.4 & $\begin{array}{l}20 \\
20\end{array}$ & $\begin{array}{c}228.2 \\
210.2^{* *}\end{array}$ & 0.029 & 0.095 & 68 \\
\hline Enniatin B1 & $\begin{array}{c}\text { Merck } \\
\text { (Darmstadt, Germany) }\end{array}$ & {$[\mathrm{M}+\mathrm{H}]^{+}$} & 654.4 & $\begin{array}{l}23 \\
23\end{array}$ & $\begin{array}{c}228.2 \\
210.2 * *\end{array}$ & 0.046 & 0.151 & 80 \\
\hline
\end{tabular}

* Limit of detection (LOD) and limit of quantification (LOQ) were estimated according to a procedure suggested by an EU guidance document by spiking 10 blank samples to $1.9 \mu \mathrm{g} / \mathrm{L}$ of each toxin. ** Product ion used as quantifier. ${ }^{* * *}$ Spike level of $300 \mu \mathrm{g} / \mathrm{L}$ at the beginning of the extraction procedure. 
An Agilent (Waldbronn, Germany) 1290 Infinity II HPLC system linked to an Agilent 6460 Triple Quad was employed for toxin quantification. Separation was carried out on an Agilent Zorbax Eclipse C18 column with a $1.8-\mu \mathrm{m}$ particle size and $100 \times 2.1 \mathrm{~mm}$. Details concerning the mass transition, recoveries, and the limits of detection and quantification can be found in Table 3.

\subsection{Statistical Analysis}

All Pearson's correlation coefficients and statistical analysis were done using the open source software RStudio. For significant statistical differences in the fungal DNA and mycotoxins contents, standard analysis of variance (ANOVA) was applied on the data. This analysis was followed by Tukey's honest significance test with a significance level of $p \leq 0.05, n=3$ ("agricolae" package in RStudio).

Author Contributions: Conceptualization, E.A., H.-W.D. and A.-K.M.; methodology, E.A., J.B., A.R., P.K., H.-W.D. and A.-K.M.; formal analysis, E.A., J.B., A.R., P.K. and A.-K.M.; investigation, E.A., J.B., A.R., P.K. and A.-K.M.; resources, P.K., H.-W.D. and A.-K.M.; data curation, E.A., J.B., A.R., P.K. and A.-K.M.; writing-original draft preparation, E.A.; writing-review and editing, E.A., J.B., A.R., P.K. and A.-K.M.; visualization, E.A.; supervision, P.K., H.-W.D. and A.-K.M.; project administration, P.K., H.-W.D. and A.-K.M.; funding acquisition, P.K., H.-W.D. and A.-K.M.

Funding: The authors appreciate the financial support of the German Federal Ministry of Education and Research (BMBF) within the scope of the competitive grants program "Networks of excellence in agricultural and nutrition research-CROP.SENSe.net" (Funding code: 0315529), Junior Research Group "Hyperspectral phenotyping of resistance reactions of barley" and the Catholic Academic Exchange Service (KAAD), Scholarship Program 2.

Acknowledgments: The authors would like to thank Heike Rollwage from University of Goettingen for her technical support in fungal DNA quantification, and sincere thanks go to Richard A. Sikora from the University of Bonn for revising the manuscript. This manuscript is dedicated to our co-author Professor Heinz-Wilhelm Dehne, an important mentor who passed away too early on the 23 May 2019.

Conflicts of Interest: The authors declare that they have no conflict of interest. The funders had no role in the design of the study; in the collection, analyses, or interpretation of data; in the writing of the manuscript, or in the decision to publish the results.

\section{References}

1. McMullen, M.; Bergstrom, G.; De Wolf, E.; Dill-Macky, R.; Hershman, D.; Shaner, G.; Van Sanford, D. A unified effort to fight an enemy of wheat and barley: Fusarium head blight. Plant Dis. 2012, 96, 1712-1728. [CrossRef] [PubMed]

2. Talas, F.; Parzies, H.K.; Miedaner, T. Diversity in genetic structure and chemotype composition of Fusarium graminearum sensu stricto populations causing wheat head blight in individual fields in Germany. Eur. J. Plant Pathol. 2011, 131, 39-48. [CrossRef]

3. Alkadri, D.; Rubert, J.; Prodi, A.; Pisi, A.; Manes, J.; Soler, C. Natural co-occurrence of mycotoxins in wheat grains from Italy and Syria. Food Chem. 2014, 157, 111-118. [CrossRef] [PubMed]

4. van der Lee, T.; Zhang, H.; van Diepeningen, A.; Waalwijk, C. Biogeography of Fusarium graminearum species complex and chemotypes: A review. Food Addit. Contam. Part A Chem. Anal. Control Expo. Risk Assess. 2015, 32, 453-460. [CrossRef] [PubMed]

5. Pasquali, M.; Beyer, M.; Logrieco, A.; Audenaert, K.; Balmas, V.; Basler, R.; Boutigny, A.-L.; Chrpová, J.; Czembor, E.; Gagkaeva, T.; et al. A European database of Fusarium graminearum and F. culmorum trichothecene genotypes. Front. Microbiol. 2016, 7, 406. [CrossRef] [PubMed]

6. Alvarez, C.L.; Azcarate, M.P.; Pinto, V.F. Toxigenic potential of Fusarium graminearum sensu stricto isolates from wheat in Argentina. Int. J. Food Microbiol. 2009, 135, 131-135. [CrossRef] [PubMed]

7. Umpiérrez-Failache, M.; Garmendia, G.; Pereyra, S.; Rodríguez-Haralambides, A.; Ward, T.J.; Vero, S. Regional differences in species composition and toxigenic potential among Fusarium head blight isolates from Uruguay indicate a risk of nivalenol contamination in new wheat production areas. Int. J. Food Microbiol. 2013, 166, 135-140. [CrossRef] [PubMed]

8. Ward, T.J.; Clear, R.M.; Rooney, A.P.; O’Donnell, K.; Gaba, D.; Patrick, S.; Starkey, D.E.; Gilbert, J.; Geiser, D.M.; Nowicki, T.W. An adaptive evolutionary shift in Fusarium head blight pathogen populations is driving the rapid spread of more toxigenic Fusarium graminearum in North America. Fungal Genet. Biol. 2008, 45, 473-484. [CrossRef] [PubMed] 
9. Kelly, A.C.; Clear, R.M.; O’Donnell, K.; McCormick, S.; Turkington, T.K.; Tekauz, A.; Gilbert, J.; Kistler, H.C.; Busman, M.; Ward, T.J. Diversity of Fusarium head blight populations and trichothecene toxin types reveals regional differences in pathogen composition and temporal dynamics. Fungal Genet. Biol. 2015, 82, 22-31. [CrossRef]

10. Varga, E.; Wiesenberger, G.; Hametner, C.; Ward, T.J.; Dong, Y.; Schöfbeck, D.; McCormick, S.; Broz, K.; Stückler, R.; Schuhmacher, R.; et al. New tricks of an old enemy: Isolates of Fusarium graminearum produce a type a trichothecene mycotoxin. Environ. Microbiol. 2015, 17, 2588-2600. [CrossRef]

11. Schaad, N.W.; Frederick, R.D. Real-time PCR and its application for rapid plant disease diagnostics. Can. J. Plant Pathol. 2002, 24, 250-258. [CrossRef]

12. Krska, R.; Schubert-Ullrich, P.; Molinelli, A.; Sulyok, M.; Macdonal, S.; Crews, C. Mycotoxin analysis: An update. Food Addit. Contam. 2008, 25, 152-163. [CrossRef] [PubMed]

13. Meneely, J.P.; Ricci, F.; van Egmond, H.P.; Elliott, C.T. Current methods of analysis for the determination of trichothecene mycotoxins in food. Trends Anal. Chem. 2011, 30, 192-203. [CrossRef]

14. Del Fiore, A.; Reverberi, M.; Ricelli, A.; Pinzari, F.; Serranti, S.; Fabbri, A.A.; Bonifazi, G.; Fanelli, C. Early detection of toxigenic fungi on maize by hyperspectral imaging analysis. Int. J. Food Microbiol. 2010, 144, 64-71. [CrossRef] [PubMed]

15. Wang, W.; Heitschmidt, G.W.; Windham, W.R.; Feldner, P.; Ni, X.; Chu, X. Feasibility of detecting aflatoxin B1 on inoculated maize kernels surface using VIS/NIR hyperspectral imaging. J. Food Sci. 2015, 80, 116-122. [CrossRef] [PubMed]

16. Kimuli, D.; Lawrence, K.C.; Yoon, S.-C.; Wang, W.; Heitschmidt, G.W.; Zhao, X. A SWIR hyperspectral imaging method for classifying Aflatoxin B1 contaminated maize kernels. In Proceedings of the 2017 ASABE Annual International Meeting, Spokane, WA, USA, 16-19 July 2017. Paper No. 1700764.

17. Chu, X.; Wang, W.; Yoon, S.-C.; Ni, X.; Heitschmidt, G.W. Detection of aflatoxin B1 (AFB1) in individual maize kernels using short wave infrared (SWIR) hyperspectral imaging. Biosyst. Eng. 2017, 157, 13-23. [CrossRef]

18. Singh, C.B.; Jayas, D.S.; Paliwal, J.; White, N.D.G. Detection of sprouted and midge-damaged wheat kernels using near-infrared hyperspectral imaging. In Proceedings of the CSBE/SCGAB 2008 Annual Conference, North Vancouver, BC, Canada, 13-16 July 2008. Paper No. CSBE08-198.

19. Singh, C.B.; Jayas, D.S.; Paliwal, J.; White, N.D.G. Detection of insect-damaged wheat kernels using near-infrared hyperspectral imaging. J. Stored Prod. Res. 2009, 45, 151-158. [CrossRef]

20. Peiris, K.H.S.; Pumphrey, M.O.; Dowell, F.E. NIR absorbance characteristics of deoxynivalenol and of sound and Fusarium- damaged wheat kernels. J. Near Infrared Spectrosc. 2009, 17, 213-221. [CrossRef]

21. Peiris, K.H.S.; Pumphrey, M.O.; Dong, Y.; Maghirang, E.B.; Berzonsky, W.; Dowell, F.E. Near-infrared spectroscopic method for identification of Fusarium head blight damage and prediction of deoxynivalenol in single wheat kernels. Cereal Chem. 2010, 87, 511-517. [CrossRef]

22. Kautzman, M.E.; Wickstrom, M.L.; Scott, T.A. The use of near infrared transmittance kernel sorting technology to salvage high quality grain from grain downgraded due to Fusarium damage. Anim. Nutr. 2015, 1, 41-46. [CrossRef]

23. Beyer, M.; Pogoda, F.; Ronellenfitsch, F.K.; Hoffmann, L.; Udelhoven, T. Estimating deoxynivalenol contents of wheat samples containing different levels of Fusarium-damaged kernels by diffuse reflectance spectrometry and partial least square regression. Int. J. Food Microbiol. 2010, 142, 370-374. [CrossRef] [PubMed]

24. Delwiche, S.R.; Hareland, G.A. Detection of scab-damaged hard red spring wheat kernels by near-infrared reflectance. Cereal Chem. 2004, 81, 643-649. [CrossRef]

25. Delwiche, S.D.; Kim, M.S.; Dong, Y. Fusarium damage assessment in wheat kernels by VIS/NIR hyperspectral imaging. Sens. Instrum. Food Qual. Saf. 2011, 5, 63-71. [CrossRef]

26. Dowell, F.E.; Ram, M.S.; Seitz, L.M. Predicting scab, vomitoxin, and ergosterol in single wheat kernels using near-infrared spectroscopy. Cereal Chem. 1999, 76, 573-576. [CrossRef]

27. Shahin, M.A.; Symons, S.J. Detection of Fusarium damage in Canadian wheat using visible/near-infrared hyperspectral imaging. J. Food Meas. Charact. 2012, 6, 3-11. [CrossRef]

28. Yang, I.C.; Delwiche, S.R.; Chen, S.; Lo, Y.M. Enhancement of Fusarium head blight detection in free-falling wheat kernels using a bichromatic pulsed LED design. Opt. Eng. 2009, 48, 023602.

29. Jirsa, O.; Polišenská, I. Identification of Fusarium damaged wheat kernels using image analysis. Acta Univ. Agric. Silvic. Mendel. Brun. 2011, 59, 125-130. [CrossRef] 
30. Barbedo, J.G.A.; Tibola, C.S.; Fernandes, J.M.C. Detecting Fusarium head blight in wheat kernels using hyperspectral imaging. Biosyst. Eng. 2015, 131, 65-76. [CrossRef]

31. McMullen, M.; Jones, R.; Gallenberg, D. Scab of wheat and barley: A re-emerging disease of devastating impact. Plant Dis. 1997, 81, 1340-1348. [CrossRef]

32. Alisaac, E.; Behmann, J.; Kuska, M.T.; Dehne, H.W.; Mahlein, A.K. Hyperspectral quantification of wheat resistance to Fusarium head blight: Comparison of two Fusarium species. Eur. J. Plant Pathol. 2018, 152, 869-884. [CrossRef]

33. Mahlein, A.-K.; Alisaac, E.; Al Masri, A.; Behmann, J.; Dehne, H.-W.; Oerke, E.-C. Comparison and combination of thermal, fluorescence and hyperspectral imaging for monitoring Fusarium head blight of wheat on spikelet scale. Sensors 2019, 19, 2281. [CrossRef] [PubMed]

34. Mahlein, A.-K.; Kuska, M.T.; Behmann, J.; Polder, G.; Walter, A. Hyperspectral sensors and imaging technologies in phytopathology: State of the art. Annu. Rev. Phytopathol. 2018, 56, 535-558. [CrossRef] [PubMed]

35. Boyacioglu, D.; Hettiarachchy, N.S. Changes in some biochemical components of wheat grain that was infected with Fusarium graminearum. J. Cereal Sci. 1995, 21, 57-62. [CrossRef]

36. Siuda, R.; Grabowski, A.; Lenc, L.; Ralcewicz, M.; Spychaj-Fabisiak, E. Influence of the degree of fusariosis on technological traits of wheat grain. Int. J. Food Sci. Technol. 2010, 45, 2596-2604. [CrossRef]

37. Kreuzberger, M.; Limsuwan, S.; Eggert, K.; Karlovsky, P.; Pawelzik, E. Impact of Fusarium spp. infection of bread wheat (Triticum aestivum L.) on composition and quality of flour in association with EU maximum level for deoxynivalenol. J. Appl. Bot. Food Qual. 2015, 88, 177-185.

38. Wieser, H. Simple determination of gluten protein types in wheat flour by turbidimetry. Cereal Chem. 2000, 77, 48-52. [CrossRef]

39. Wang, J.; Wieser, H.; Pawelzik, E.; Weinert, J.; Keutgen, A.J.; Wolf, G.A. Impact of the fungal protease produced by Fusarium culmorum on the protein quality and breadmaking properties of winter wheat. Eur. Food Res. Technol. 2005, 220, 552-559. [CrossRef]

40. Nightingale, M.J.; Marchylo, B.A.; Clear, R.M.; Dexter, J.E.; Preston, K.R. Fusarium head blight: Effect of fungal proteases on wheat storage proteins. Cereal Chem. 1999, 76, 150-158. [CrossRef]

41. Gärtner, B.H.; Munich, M.; Kleijer, G.; Mascher, F. Characterisation of kernel resistance against Fusarium infection in spring wheat by baking quality and mycotoxin assessments. Eur. J. Plant Pathol. 2008, 120, 61-68. [CrossRef]

42. Hellin, P.; Duvivier, M.; Dedeurwaerder, G.; Bataille, C.; De Proft, M.; Legrève, A. Evaluation of the temporal distribution of Fusarium graminearum airborne inoculum above the wheat canopy and its relationship with Fusarium head blight and DON concentration. Eur. J. Plant Pathol. 2018, 151, 1049-1064. [CrossRef]

43. Castañares, E.; Albuquerque, D.R.; Dinolfo, M.I.; Pinto, V.F.; Patriarca, A.; Stenglein, S.A. Trichothecene genotypes and production profiles of Fusarium graminearum isolates obtained from barley cultivated in Argentina. Int. J. Food Microbiol. 2014, 179, 57-63. [CrossRef] [PubMed]

44. Nielsen, L.K.; Cook, D.J.; Edwards, S.G.; Ray, R.V. The prevalence and impact of Fusarium head blight pathogens and mycotoxins on malting barley quality in UK. Int. J. Food Microbiol. 2014, 179, 38-49. [CrossRef] [PubMed]

45. Siou, D.; Gelisse, S.; Laval, V.; Repincay, C.; Canales, R.; Suffert, F.; Lannou, C. Effect of wheat spike infection timing on Fusarium head blight development and mycotoxin accumulation. Plant Pathol. 2014, 63, 390-399. [CrossRef]

46. Beccari, G.; Arellano, C.; Covarelli, L.; Tini, F.; Sulyok, M.; Cowger, C. Effect of wheat infection timing on Fusarium head blight causal agents and secondary metabolites in grain. Int. J. Food Microbiol. 2019, 290, 214-225. [CrossRef] [PubMed]

47. Delwiche, S.R. Classification of scab-and other mold-damaged wheat kernels by near-infrared reflectance spectroscopy. Trans. ASAE 2003, 46, 731-738. [CrossRef]

48. Lancashire, P.D.; Bleiholder, H.; van den Boom, T.; Langeluddecke, P.; Stauss, R.; Weber, E.; Witzenberger, A. A uniform decimal code for growth stages of crops and weeds. Ann. Appl. Biol. 1991, 119, 561-601. [CrossRef]

49. Schilling, A.G.; Möller, E.M.; Geiger, H.G. Polymerase chain reaction-based assays for species-specific detection of Fusarium culmorum, F. graminearum and F. avenaceum. Phytopathology 1996, 86, 515-522. [CrossRef] 
50. Nicholson, P.; Simpson, D.R.; Weston, G.; Rezanoor, H.N.; Lees, A.K.; Parry, D.W.; Joyce, D. Detection and quantification of Fusarium culmorum and Fusarium graminearum in cereals using PCR assays. Physiol. Mol. Plant Pathol. 1998, 53, 17-37. [CrossRef]

51. Parry, D.W.; Nicholson, P. Development of a PCR assay to detect Fusarium poae in wheat. Plant Pathol. 1996, 45, 383-391. [CrossRef] 